\title{
Study on Practical Ability Training of Computer Science and Technology Specialty in Colleges
}

\author{
Li Miao, Wenbo Jiang, Jing Liu* \\ Haikou College of Economics, Haikou, Hainan, 571127
}

Keywords: Practical Ability Training, Computer Science and Technology, College Education

\begin{abstract}
The characteristics of the post-informatization era are characterized by the use of information, the value of its application and the social and economic role that its information has. On the basis of analyzing and evaluating the present situation of information technology talent cultivation in the information era, this study combines multidisciplinary knowledge of political economy, political science and management science with the methods of literature research, questionnaire investigation and comparative research to reveal In the era of post-information technology in our country information technology talents training and social needs arising from the contradictions and problems, post-information age I information technology personnel training target positioning and training programs put forward ideas and conduct of the feasibility study and analysis.
\end{abstract}

\section{Introduction}

The field of information technology belongs to the category of high-tech. Its industry belongs to the "sunrise industry." The information technology industry is the fastest-growing and most active industry in our country. It has been the forerunner in the industrial arena in the world and is an important support for the growth of the national economy. However, in order to realize the development strategy guideline of "driving industrialization with informatization" and enable the information technology industry to maintain a strong momentum of development for a long period of time, we must rely on the contingent of qualified personnel, including the contingent of highly creative and highly qualified professionals ; Outstanding technical personnel who can undertake the development and innovation of key basic core technologies; and the first-line high-quality and practical talents with high-level skilled workers as the mainstay. However, at present, the original training mode, curriculum, faculty, assessment and evaluation system of information technology talents in colleges and universities have not been able to adapt to the speed of development of the information industry and the market demand for qualified personnel. Then the advent of the information age will make this kind of maladjustment more prominent. Therefore, the reform of university information technology personnel training is imperative!

\section{New demands for the training of information technology personnel}

With the rapid development of the national strategic industries represented by communications, information technology and computer technology, the rapid advancing of the information industry has created challenges as well as opportunities for the talent strategy and personnel training in the post-information age and how to adapt to the times. The trend of training new generation of talent has become an urgent problem to be faced. To reflect the use of information as the main characteristics of post-information age, for the discoverer of information value and the user talent one by one, put forward higher requirements. In the context of globalization of the information revolution, along with the economic and social transformation that China is experiencing, it has transformed itself from a populous nation into a powerful human resource and a strong country with talented people. The society has raised new topics for personnel training of higher education. Universities face new social needs and challenges themselves. In the industrial age, education 
focused on training educated people with basic skills to meet the needs of industrial society. The labor force in the era of knowledge requires low cost and high efficiency. The demand for talent is also becoming more and more integrated and high-level. Not only requires practitioners to master a combination of skills, but also requires them to have a higher level of knowledge and expert thinking, complex communication and higher application skills, the judge and evaluation of talent from practitioners also have comprehensive skills, Professional knowledge and ability to innovate and so on.

\section{The Development Track of Chinese Universities and Talents Training New Challenges}

Standing at the turn of the century and looking forward to new technologies in the world, what we have seen is the ever-changing information and communication technology and the vigorous development of the information and communication industry. There is no doubt that our society has entered the post-information age. In the information era, the key role of information acquisition, circulation and the information itself in building the core competitiveness is marked. In the post-information age, the competitive advantage of acquiring and possessing information is getting lower and lower, the economic role of information is gradually highlighted, and the ability to process and utilize information has replaced information itself as a key competitive factor. In terms of practice, there is a big difference between the requirements of personnel training of information technology disciplines. In terms of talent cultivation in information technology disciplines, China's postal and telecommunications colleges and universities all undergo new major changes such as "institutional transfer, expansion of schooling scale and upgrading of name", how to expand the school's thinking, improve the level of running a school, take the initiative to adapt to the post-information age, Economic and social development and the trend of internationalization of higher education requirements of the times become such an important issue for higher education workers in the new century thinking and exploration of post-information age information technology disciplines talent training is still inseparable from the talent and application of this More and more educators have realized that strengthening cooperation in production, learning and research is an important way to promote scientific and technological innovation and transform scientific and technological achievements into real productive forces and an important measure to raise the level of scientific research and personnel training and speed up development. The establishment of a degree of cooperation from the "school cooperation", "school-enterprise alliance," school cooperation "," independent development "," into the park "and other modes as the basis for cooperation in production and research cooperation. Therefore, The era of information technology disciplines training problems, become postal and telecommunications higher education At the same time, how to make the information technology disciplines more practical training and application of the combination of production, teaching and research cooperation more reasonable to cultivate both the theory, but also understand the application of high-quality specialized technical personnel, the full postal and telecommunications An Important Factor for the Differences in Advantages and Disadvantages of Colleges and Universities.

For a long time, under the background of historical development and traditional ideology and culture, the basic characteristics of higher education personnel training in our country are as follows: emphasis on system knowledge transfer, solid foundation knowledge, lack of practical experience and weak hands-on ability; promotion of basic standards , Training the same size, ignoring the personality development of educated, the lack of top-notch innovative talents. Compared with the education level of educated workers in developed countries, we find that the reason why undergraduates in domestic universities lack the critical creative thinking ability is not that foreign universities teach more or better creativity, but because These countries inhibit the development of this capacity less than our schools. In the post-information age, higher education is no longer a mere medium for obtaining knowledge and information. It must also be a means by which educators can freely use various knowledge and skills to cultivate independent thinking, innovative awareness and ability to utilize. Competition in the final analysis is the quality of competition. Improving the quality of education is the inevitable choice to realize the educational development in our country. 
The socio-economic changes brought about by the scientific and technological revolution and the knowledge-based economy call for the university to cultivate a large number of creative talents with comprehensive qualities and outstanding individual characteristics for the society.

\section{Information technology personnel ability to innovate}

The most important feature of innovation ability is originality. Innovative skills are a kind of hands-on ability that reflects the creative subject's behavior skills formed under the guidance and constraint of innovative intelligence. Innovative spirit is a relatively stable positive psychological tendency that an individual has for creative activities. Innovative quality is the main body based on the innate, The stable quality formed through the internalization of the innovative knowledge, innovative technologies and innovative qualities gained externally; and the innovation motivation is based on the innovative intentions and aspirations arising from the social and individual needs. In the educational process of rational cognitive process, educators should launch all educational methods, create all educational environments, tap all educational resources, and develop the potentials of educated people to the greatest extent possible. These potentials are the original elements of the innovative ability of the educated we seek. In personnel training, higher education should at least carry out three to tap potential, pay attention to cultural influence, to build a civilized society, and bear the brunt of the responsibility should be made to all educated creative ability or potential ability to maximize their play A rich fruit. The training of high-level communication talents and their innovative ability has become an indispensable and important element in the post-information age development process. Therefore, the training of high-level communication talents should have higher requirements. The train of thought is to train the original students' Innovative ability.

Different from general technological innovation, primitive innovation started with problems and accumulated in pregnancy. Basic research is the accumulation of history, possible innovation. It often leaps and changes in the "chain" of progressive accumulation. Of course, it must be emphasized that the accumulation of only the original premise, but not necessarily original. Original innovation is through scientific research and development, access to more scientific discoveries and technological inventions. From this, we can see that the innovation of knowledge and technology is the main measure of the country's original innovation, and it is also the intrinsic motivation to promote scientific and technological progress. Knowledge innovation with basic characteristics comes mainly from universities and research institutes, which focus on the research of nature and obtain new discoveries. The technological innovation with the application characteristics mainly comes from the enterprises. It focuses on transforming the basic scientific research achievements into Technical services to humanity. The key to the effective convergence between knowledge innovation and technology innovation lies in whether the two innovation entities are organically combined. In other words, enterprises that are the subject of technological innovation at the application level take initiative to make demands on universities and research institutes to obtain original achievements and realize original innovation. On the other hand, universities and research institutes, as the main body of knowledge innovation, Cooperate with enterprises and participate in the process of technological innovation, solve problems of technological innovation with knowledge innovation achievements, and transform knowledge innovation achievements in enterprises. In this process of "one in one out", the original innovative ability of individuals who successfully completed this interactive process is gradually being developed and tapped, influenced by the core elements. Under the action of the virtuous circle, the individual's innovative ability is gradually idealized The With the rapid development of science and technology, the original innovation achievements will emerge endlessly. The science and technology that is most rapidly developing and most widely affected by information science will continue to make new breakthroughs. Future science and technology are likely to form new frontiers of science in information science and other fields and achieve new breakthroughs. The series of original innovations brought about by modern science and technology will lead to fundamental changes in productivity and production relations. 


\section{Conclusion}

This era of our life follows the evolution of information technology and the tide of information revolution are undergoing unprecedented changes. We bathe the beautiful life and the sunshine and rain brought by the development of informationization to the human world. Since the beginning of the year, we have experienced the era of components marked by functionality, the era of large-scale computers marked by systematization, the era of personal computers and application terminals marked by independence, and the Internet era marked by commonality. The calculation model that society almost follows a program every fifteen years as a development cycle is irreversibly entered the information age along this historical trajectory. The current world economic development is facing a new historical turning point. The tidal wave of the third information revolution is making ugly all over the world. However, the era of the Internet of Things marked by anthropomorphism has been vigorously coming. Informationization has gone through dozens of years Years of development began to enter a new stage of historical development or post-information era, the application of the Internet of Things will be an important feature of this stage.

\section{Acknowledgements}

Project Title: Hainan Province, higher education and teaching reform research key project "Internet of Things construction and wisdom of Hainan research and practice"

Project Number: Hnjg2016ZD-22

\section{References}

[1] Hu Chengjuan. Cultivation of innovative abilities of computer science and technology [J]. Business Review 2011 (01)

[2] Ye Junmin, YangYan, Li Rong, Wang Jinghua. Talking about the Cultivation of Talents in Normal University Students Majoring in Computer Science and Technology [J] .Computer Education, 2011

[3] Wang Ruilan. Relying on internship base training college students engineering practice ability [J]. Laboratory Research and Exploration. 2011 (04)

[4] Jiang Yi, Jiang Ziyan. Building automation teaching aimed at training engineering practice ability [J] .HKV. 2011 (05)

[5] Zhou Qiming. Computer Science and Technology Practice Teaching Links [J]. Contemporary Theory and Practice of Education. 2011 (05)

[6] Zhang Gang. Computer science and technology sub-direction training programs [J]. Computer Education. 2011 (07) 